\title{
Impact of intensive horticulture practices on groundwater content of nitrates, sodium, potassium, and pesticides
}

\author{
Armindo Melo • Edgar Pinto • Ana Aguiar • \\ Catarina Mansilha • Olívia Pinho • \\ Isabel M. P. L. V. O. Ferreira
}

Received: 17 December 2010 / Accepted: 27 July 2011 /Published online: 9 August 2011

(C) Springer Science+Business Media B.V. 2011

\begin{abstract}
A monitoring program of nitrate, nitrite, potassium, sodium, and pesticides was carried out in water samples from an intensive horticulture area in a vulnerable zone from north of Portugal. Eight collecting points were selected and water-analyzed in five sampling campaigns, during 1 year. Chemometric techniques, such as cluster analysis, principal component analysis (PCA), and discriminant analysis, were used in order to understand the impact of
\end{abstract}

A. Melo $\cdot$ E. Pinto $\cdot$ O. Pinho $\cdot$

I. M. P. L. V. O. Ferreira $(\bowtie)$

REQUIMTE/Departamento de Ciências Químicas,

Laboratório de Bromatologia e Hidrologia da Faculdade de

Farmácia da Universidade do Porto,

Porto, Portugal

e-mail: isabel.ferreira@ff.up.pt

A. Aguiar

REQUIMTE/Faculdade de

Ciências da Universidade do Porto,

Porto, Portugal

C. Mansilha

Instituto Nacional de Saúde Dr. Ricardo Jorge,

Porto, Portugal

O. Pinho

Faculdade de Ciências da Nutrição e Alimentação da

Universidade do Porto,

Porto, Portugal

C. Mansilha

REQIMTE/Universidade do Porto,

Porto, Portugal intensive horticulture practices on dug and drilled wells groundwater and to study variations in the hydrochemistry of groundwater. PCA performed on pesticide data matrix yielded seven significant PCs explaining $77.67 \%$ of the data variance. Although PCA rendered considerable data reduction, it could not clearly group and distinguish the sample types. However, a visible differentiation between the water samples was obtained. Cluster and discriminant analysis grouped the eight collecting points into three clusters of similar characteristics pertaining to water contamination, indicating that it is necessary to improve the use of water, fertilizers, and pesticides. Inorganic fertilizers such as potassium nitrate were suspected to be the most important factors for nitrate contamination since highly significant Pearson correlation $(r=0.691, P<0.01)$ was obtained between groundwater nitrate and potassium contents. Water from dug wells is especially prone to contamination from the grower and their closer neighbor's practices. Water from drilled wells is also contaminated from distant practices.

Keywords Intensive horticulture Pesticides ·

Nitrates · Groundwater $\cdot$ Chemometric analysis

\section{Introduction}

Groundwater is a valuable natural resource and as such should be protected from deterioration and 
chemical pollution. The quality of groundwater, concerning nitrate, and pesticides content is assessed in the European Union (Directive 2006/118/EC, 2006). Groundwater is considered to have a good chemical quality when nitrate levels do not exceed $50 \mathrm{mg} / \mathrm{l}$, while those of pesticides and their metabolites do not exceed $0.1 \mu \mathrm{g} / \mathrm{l}$ (a total of $0.5 \mu \mathrm{g} / \mathrm{l}$ for all pesticides measured).

Nevertheless, other parameters concerning groundwater composition are important, namely the content of sodium and potassium that rarely exceeds $100 \mathrm{mg} / 1$ (Na) and $90 \mathrm{mg} / \mathrm{l}(\mathrm{K})$, respectively. $\mathrm{Na} / \mathrm{K}$ ratio in weakly mineralized water usually ranges from 0.2 to 0.9 , but the ratio, usually, increases along rising mineralization (usually up to 30-200) (Szymanska-Pulikowska 2008).

Pollution by intensive agriculture practices is a major risk to the planet's groundwater resources (Bouwer 2000; Chowdary et al. 2005; Kundu et al 2009). The changes in agricultural practices during twentieth century (use of fertilizers, simplification of the landscape, mechanization, drainage) have significantly contributed to increase the concentrations of pollutant substances in groundwater whose main sources of pollutants are agrochemicals, fertilizers, and salts contained in irrigation leaching.

In NW Portugal, a small region between Esposende and Vila do Conde is dedicated to intensive horticulture practices. This region is included in a vulnerable zone (VZ1) regulated by Council Directive 91/676/EEC (1991) and Portaria 556/2003. Vulnerable area no. 1 is delimited by the Atlantic Ocean on the west, A28 highway on the east, the river Cávado, and river Ave on the north and south, respectively, with an encoded area of $55 \mathrm{~km}^{2}$. The high level of nitrates is the reason why this zone was classified as vulnerable. Nitrates present in well's water comes from nitrogen fertilizers used in agriculture mainly in vegetable production, but in VZ1, there are also counties used for cattle and cattle forage crops (Agostinho 2006). Additionally, some reports correlate the concentrations of nitrate with those of pesticides (Silva et al. 2006; Squillace et al. 2002; Gonçalves et al. 2007); thus, groundwater pesticide contamination is also a relevant topic to be investigated.

Vegetables commonly cultivated in VZ1 in the open-air are cabbages (Bassica oleracea L. var. costata and B. oleracea L. var. capitata) and turnip (Brassica napus) in winter and lettuce (Lactuca sativa), garlic (Allium sativum), onion (Allium cepa), parsley (Petroselinum crispum), carrot (Daucus carota), and pumpkin (Cucurbita pepo) in spring-summer. In greenhouses, the main cultures are lettuce and turnip in winter and tomato (Lycopersicon esculentum), sweet pepper (Capsicum annuum), green beans (Phaseolus vulgaris), and cucumber (Cucumis sativus) in springsummer. The production system used in this region since the 1960s is based on high inputs of water, fertilizers, and pesticides. It is a typical case of industrial agriculture as it can be characterized by agro chemically based, monocultural, and market-oriented (Altieri and Nicholls 2005). Pest management is exceedingly difficult.

Greenhouse mild temperatures and high humidity promotes fungi and insect development. Key pests in horticulture are the diseases downy mildew and botrytis gray mold and the insects aphids. Growers prevent these pests using authorized fungicides and insecticides (azoxystrobin, acetamiprid, cyprodinil, fenhexamid, fludioxonil, folpet, iprodione, metalaxyl, pirimicarb, and thiamethoxam). In general, herbicides are not required since black plastics are used to prevent weeds.

Regular monitoring programs are required for reliable estimates of pollutants and to study variations in the hydrochemistry of groundwater (Andrade et al. 2005; Singh et al. 2005). Consequently, a complex data matrix is obtained including a large number of parameters, which are often difficult to highlight meaningful conclusions (Wunderlin et al. 2001; Simeonov et al. 2003). The multidimensional data analysis methods are very attractive in environmental studies dealing with measurements and monitoring, looking for possible grouping and sources of data variation.

The most common multidimensional data analysis methods used are cluster analysis (CA), factor analysis/principal component analysis (FA/PCA), and discriminant analysis (DA) which have been used to identify important components/sources that explain the variations in water quality and influence the water system. Usually, CA is carried out to reveal specific links between collecting points, while FA/PCA is used to identify distribution of pollutants on environmental systems (Singh et al. 2005; Gangopadhyay et al. 2001). In contrast to the exploratory features of CA, DA provides statistical classification of samples, and it is performed with previous knowledge of groups or clusters such as temporal or spatial grouping of 
samples. DA helps in grouping samples with common properties.

The application of such tools is expected to help rationalize confused intrinsic associations within real data and give an insight to identify the pollution sources for effective water resource management and pollution control. The present study attempts to understand the impact of intensive horticulture practices on groundwater pollution in a vulnerable zone. For this purpose nitrates, nitrites, sodium, potassium, and pesticides concentration in groundwater from dug and drilled wells was monitored during 1 year to examine the distribution of the compounds under study and identify areas and sources of contamination.

\section{Material and methods}

Background of the studied area

From 1890 to the middle of the twentieth century, the coastline between Esposende and Vila do Conde was modulated in a unique system used for vegetable production called masseiras. Previously, it was an area with pine plantation. Farmers removed thousands of tonnes of sand, creating small fields some meters below the initial level. These fields were protected from the wind, and the climate of the masseira resembles that of a greenhouse. Vines were cultivated on the slopes to help stabilize the sand and also to produce grapes for wine. As, in general, the groundwater is just below the soil, each field could have its own well and with a pump, or just a bucket, water could be carried easily to the field to irrigate vegetables. Farmers have been obliged to open channels to drain the excess of water after winter rainfall.

Since the 1980s, the masseiras are disappearing. The high prices paid for sand, for construction projects, force farmers to sell it. In masseiras, now open and unprotected to the winds, they constructed plastic greenhouses. They can easily access the field which facilitates the use of tractors. These are the main reasons why masseiras have almost disappeared given place to "enlarged masseiras with greenhouses" that allows the production of millions tones of vegetables. To have high productions, growers have been using large amounts of water, fertilizers, and pesticides.
VZ1 has $55 \mathrm{~km}^{2}$ of sandy soils classified mainly as Cambisoils (28.8\%) and Arenosols (24.6\%) (Agostinho 2006). A dry season can be distinguished from April to September and a wet season lasting approximately from October to March accounting for around $75 \%$ of total annual rainfall (Gonçalves et al. 2006).

Selection of water collecting points

A map depicting all the VZ1 and the selected sampling sites in masseiras region is shown in Fig. 1. In this study, we have selected two dug wells in masseiras (BW1 and BW2), two dug wells (BW3 and BW4), and four drilled wells (DW1 to DW4) in "enlarged masseiras with greenhouses." Dug wells are $7,8,7$, and $10 \mathrm{~m}$ deep, respectively, for BW1, BW2, BW3, and BW4; drilled wells are 100, 120, 120 , and $70 \mathrm{~m}$ deep, respectively, for DW1, DW2, DW3, and DW4. The water of all selected wells is collected from an unconfined aquifer used for vegetable irrigation. In masseiras, water is used mainly for surface irrigation, while in greenhouses irrigation systems are mainly drip and sprinkler. Seven wells are in VZ1 and 1 (DW2) is outside, near the border. Water samples were collected in September 2009, January, March, May, and July 2010 in fields cultivated with vegetables. BW3 and DW3, dug and drilled wells, respectively, were located in the same field. The same occurred for BW4 and DW4.

Sampling and analytical work

For each sampling point, we used two different bottles: 1.51 plastic bottle (for nitrate, sodium, and potassium analyses) and 11 amber glass bottle prerinsed with ultra-pure water (for pesticides analysis). In amber bottles, the $\mathrm{pH}$ of the samples was adjusted to 3 with acetic acid (glacial) to avoid changes in sample composition by degradation processes. Samples were transported to the laboratory within one day. Samples were stored in the dark at $4^{\circ} \mathrm{C}$ until solid phase extraction (SPE) was performed within $24 \mathrm{~h}$ from their reception in all cases.

All reagents used were of analytical grade purity. Standard solutions of sodium $(1,000 \mathrm{mg} / \mathrm{l})$ and potassium $(1,000 \mathrm{mg} / \mathrm{l})$ were supplied by JenWay, England. Certified Reference Material EnviroMAT ES-H-2 CRM was purchased from SCP Science (France). 


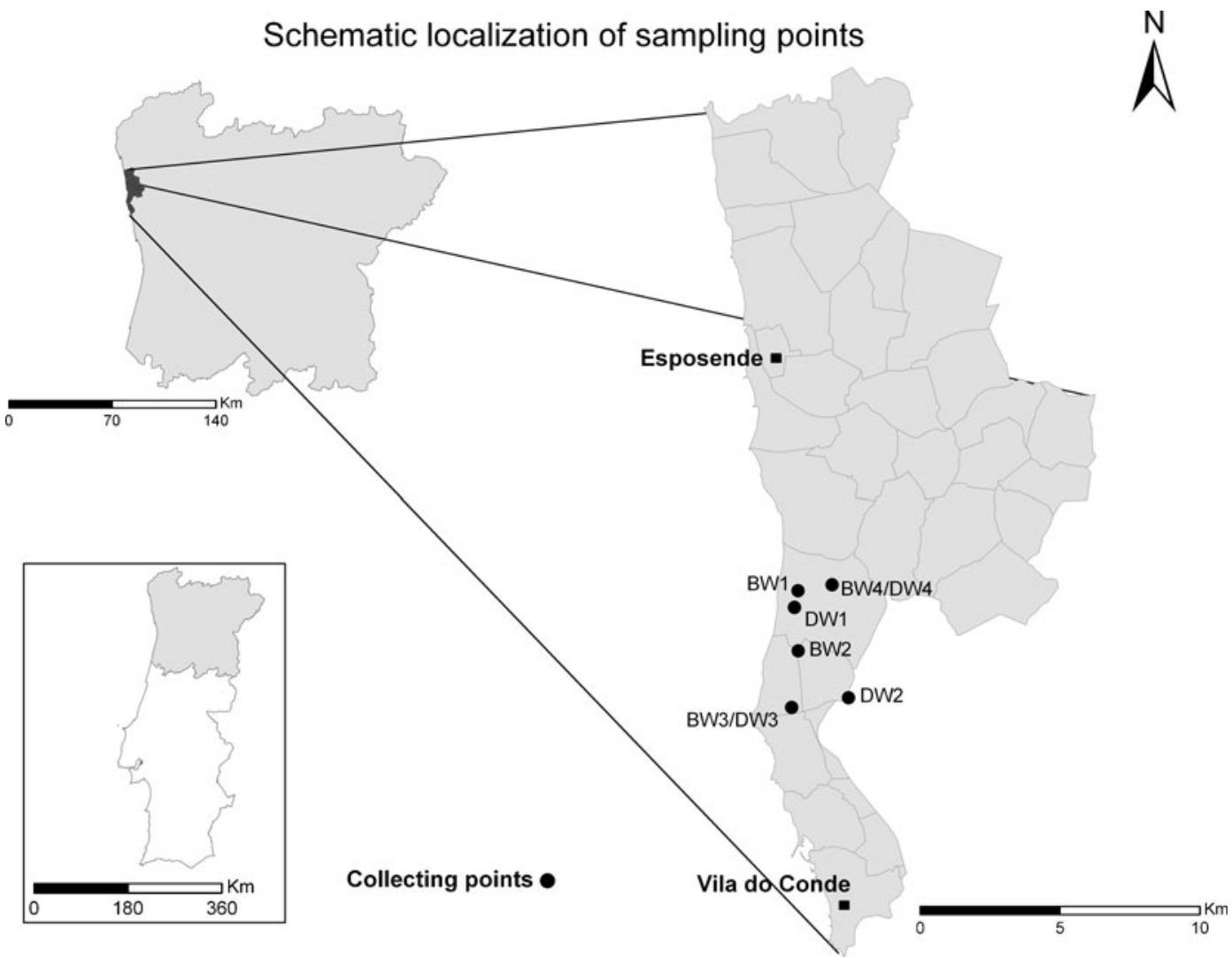

Fig. 1 Map of vulnerable zone no. 1 (VZ1) designed in the framework of the 91/676/EEC Directive and showing the distribution of the collecting points considered in the present

Nitrate and nitrite analyses were carried out by HPLC with isocratic elution with $0.01 \mathrm{M} n$-octylamine and 20\% methanol to pH 6.6 (Pinto et al. 2010). Sodium and potassium were quantified by flame photometry (Model PFP7, JenWay, England). Butane gas and air were supplied as the source of flame. The flow rate of fuel was adjusted to get a maximum sensitivity.

Pesticides were extracted by SPE using LiChrolut EN RP-18 SPE cartridges $(100 \mathrm{mg} / 200 \mathrm{mg}, 6 \mathrm{ml})$ from Merck (Darmstadt, Germany), according to the procedure previously described by Mansilha et al. (2010). Briefly, (a) conditioning step, by the sequential addition of $7 \mathrm{ml}$ of ethyl acetate, $7 \mathrm{ml}$ of methanol, and $7 \mathrm{ml}$ of Milli-Q water at a flow rate of $1 \mathrm{ml} / \mathrm{min}$; (b) loading step, by passing $500 \mathrm{ml}$ of the water sample through the cartridge at a flow of $5 \mathrm{ml} / \mathrm{min}$; (c) washing step, by rinsing the cartridge with $5 \mathrm{ml}$ water and dried by vacuum pressure during approximately $60 \mathrm{~min}$; and (d) elution performed with $2 \times 2.5 \mathrm{ml}$ of methanol and $2 \times 2.5 \mathrm{ml}$ acetonitrile, at a flow of study: four dug wells-BW1, BW2, BW3, BW4 and four drilled wells-DW1, DW2, DW3, DW4

$1 \mathrm{ml} / \mathrm{min}$. After elution, the extracts were evaporated to dryness in a rotative evaporator (Buchi/Brinkman Rotavapor RE-111 \& Water Bath B-461) and then resuspended until a final volume of $500 \mu \mathrm{l}$ in methanol and directly analyzed by GC/MS.

Chromatographic analyses of pesticides were carried out in a gas chromatograph mass spectrometer equipped with a fused-silica capillary column coated with 5\% diphenylmethylsiloxane (Mansilha et al. 2010). Twenty-eight pesticides were chosen from the list of persistent organic pollutants of the Stockholm convention (UNEP 2005) and also in accordance with European and Portuguese legislation on water quality (DGADR 2009).

\section{Description of the data set}

Limit of quantification (LOQ) is assumed to be the lowest amount of an analyte in a sample that can be quantified with acceptable precision and accuracy 
whereas the limit of detection is the lowest concentration of an analyte that can be reliably differentiated from the background noise but not necessarily quantified as an exact value. Both were calculated based on the calibration curve parameters (Mansilha et al. 2010).

Nitrates, nitrites, sodium, and potassium concentrations were expressed in milligrams per liter. The concentration values of pesticides were expressed in nanograms per liter. Spectral confirmation to ascertain pesticide identity was obtained by single or tandem mass spectrometry. The threshold limit considered to report was the respective limit of quantification. For statistical analysis, some adaptation was needed in order to have quantitative data throughout. Thus, the following criteria were adopted: Nonquantifiable results were considered as zero, since concentrations below the LOQ were considered negligible and meaningless.

\section{Statistical analysis of the monitoring results}

Exploration of results was performed by analysis of descriptive parameters, such as frequencies, values above and below a reference limit, etc. Analyses of variance were performed to find similarities and differences between samples. Then, a stepwise multivariate analysis was carried out to display the most significant patterns, looking for possible groupings and sources of data variation, as well as for their temporal and geographical distributions, through resolution and modeling of raw data.

Firstly, an unsupervised technique was applied, cluster analysis, to discover natural groupings within data and highlight similarities and differences between samples from dug and drilled wells according to collection dates. Data were organized with eight rows corresponding to the four dug wells and four drilled wells and the column vectors (X1, X2, X3, X4, X5) representing the frequency of pesticides above the LOQ in each collection date. Cluster analysis of the $\mathrm{X}$ matrix was carried out using the single linkage method with Euclidean distances which involves the scaling of distance measures by observed variable ranges.

Secondly, raw data were computed after normalization which involved dividing each value of a given variable by the standard deviation of all the values for this variable over the entire sample collection period. After normalization, all variables had the same weight because they had a mean of zero and unitary variance. Additionally, all variables that assumed a constant value equal to zero all across the samples and collecting dates were eliminated from any multivariate statistical treatment. With the purpose to reduce the "noise" present in the data, another simplification strategy was adopted: Variables with only one nonzero data value are unsuitable to display a consistent pattern linked to the environmental behavior of the pesticides and were removed from multivariate statistical treatment. These criterion led us to exclude the following pesticides from multivariate analysis: acetamiprid, aldrin, $o, p^{\prime}$-DDT, endrin, linuron, methoxychlor, $S$-metalachlor, pendimethalin, phosmet, tolylfluanid, and 2,4D. Consequently, a single matrix was formed by concentration values for each combination of variables (17 pesticides) and cases (40 samples). PCA was applied to reveal the main sources of data variance, and it allows finding out association between variables, thus reducing the dimensionality of the data set.

The PCs are the uncorrelated new variables, obtained by multiplying the original correlated variables with the eigenvector (loadings or weightings). The Bartlett's sphericity test was applied to the correlation matrix of variables for assessing the adequacy of PCA. PCs with eigenvalue $>1$ were retained. The contribution of each factor at every site (factor scores) was computed, and scores plots of first two PCs (PC1 and PC2) were constructed.

DA was applied to raw data with the objective to distinguish among variables those which have driven the formation of groups of closed related dug and drilled wells, as seen in cluster analysis. The grouping (dependent) variables were those defined by cluster analysis and nitrate, potassium, sodium, and pesticide contents constituted the independent variables. Exploration of data, descriptive statistics, ANOVA analyses, cluster analysis discriminant analysis, and principal component analysis were performed with SPSS for Windows version 18 (SPSS, Chicago, IL, USA).

\section{Results and discussion}

Nitrate, nitrite, potassium, and sodium contents in groundwater

During the studied period, the seasonal variation of nitrate, nitrite, potassium, and sodium in groundwater 
was followed, showing the dynamic of the levels, which is thought to be dependent of several factors, namely hydrogeological properties of the area, precipitation and cultural practices, particularly fertilization, and irrigation. Mean values and range of concentration during the studied period for nitrate, nitrite, potassium, and sodium organized by collecting points are presented in Table 1.

In dug wells, nitrates were detected in all water samples. Fifty percent of them exceeded legal limits of $50 \mathrm{mg} / \mathrm{l}$. It should be pointed out that wells from masseiras (BW1 and BW2) were significantly more contaminated than other wells. Two of the four drilled wells (DW2 and DW4) had water with low or undetectable nitrate levels. DW1 presented very high nitrate levels in all samples (ranging from 60 and $118 \mathrm{mg} / \mathrm{l}$ ); these levels are similar to those observed in dug wells from masseiras, except that in DW1 where $100 \%$ of the samples exceeded the limit of $50 \mathrm{mg} / \mathrm{l}$. DW3 nitrate levels ranged from 22 to $71 \mathrm{mg} / \mathrm{l}$. There was also a considerable variability within wells between sampling times. Dry season from April to September can result in concentration of nitrate in groundwater. However, the month of maximal and minimal nitrate values differed between wells indicating lack of recognizable temporal correlation and possible association with field and neighboring cultural practices and irrigation.

Nitrite content was very low or no detectable, and only the most contaminated wells (BW1 and BW2) presented content around $0.1 \mathrm{mg} / \mathrm{l}$. Highly significant Pearson correlation $(r=0.691, P<0.01)$ was obtained between groundwater nitrate and potassium contents; thus, inorganic fertilizers such as potassium nitrate were suspected to be the most important factor for nitrate contamination. However, other inorganic fertilizers could be used, namely ammonium nitrate, or for example animal manure which are other sources of contamination that can be present as apparent from DW1.

Sodium content of the groundwaters ranged from 17.4 to $92.9 \mathrm{mg} / \mathrm{l}$ (Table 1). Samples from DW3 ranged from 127.2 to $166.2 \mathrm{mg} / \mathrm{l}$ during the studied period, probably as a result of infiltration from sea water. Salinization due to seawater intrusion is one of the major threats to coastal aquifers (Russak and Sivan 2010) being a limiting factor for certain crops.
Occurrence of pesticides in groundwater

From a total of 28 pesticides (eight fungicides, 11 insecticides, and nine herbicides), five of them were not detected in any sample, acetamiprid, endrin, pendimethalin, phosmet, and 2,4D. Results from occurrence of pesticides in all water samples are summarized in Table 2. From a total of 40 samples, the most frequent fungicides were cyprodinil, metalaxyl, and azoxystrobin, followed by folpet and fludioxonil. Less abundant were fenhexamid, iprodione, and tolyfluanid. The most frequent insecticides were pirimicarb and thiamethoxam, followed by dimethoate, dieldrin, cyromazine, $o, p^{\prime}$-DDT, methoxychlor, and aldrin. Concerning herbicides, the most frequent were atrazine and terbuthylazine and their desethyl metabolites, followed by EPTC, $S$-metalachlor, and linuron. It should be pointed out that some pesticides that are not in use nowadays as they are not included in EU Pesticides database were detected in some samples: EPTC, atrazine, and terbuthylazine and their desethyl metabolites, $S$-metolachlor, aldrin, dieldrin, $o, p^{\prime}$-DDT, methoxychlor.

One of the most frequently used indicators to assess the severity of groundwater contamination is given by the percentage of detection above the $100 \mathrm{ng} / \mathrm{l}$ limit. From this standpoint, it must be emphasized that metalaxyl and thiamethoxam commonly used fungicide and insecticide, respectively, were detected in more than $20 \%$ of the samples, followed by folpet, another used fungicide. Terbuthylazine, terbuthylazinedesethyl, and desethylatrazine characteristic from maize production areas were also detected in $10 \%$ of the samples.

Considering the number of pesticides above the LOQ in each sample and the number of samples that contained pesticides above the legal limits (Table 3), fungicides and insecticides are more frequent in samples from dug wells than from drilled wells, while herbicides are less frequent except in the sample from DW1. Regarding dug wells, there are differences between the wells in masseiras (BW1 and BW2) that have more pesticides than wells in greenhouses (BW3 and BW4).

The focus of the following statistical analysis was reserved to the compounds effectively quantified in the samples (Table 3). Cluster analysis was performed in order to uncover eventual similarities on pesticide distribution or affinities among water samples. Figure 2 


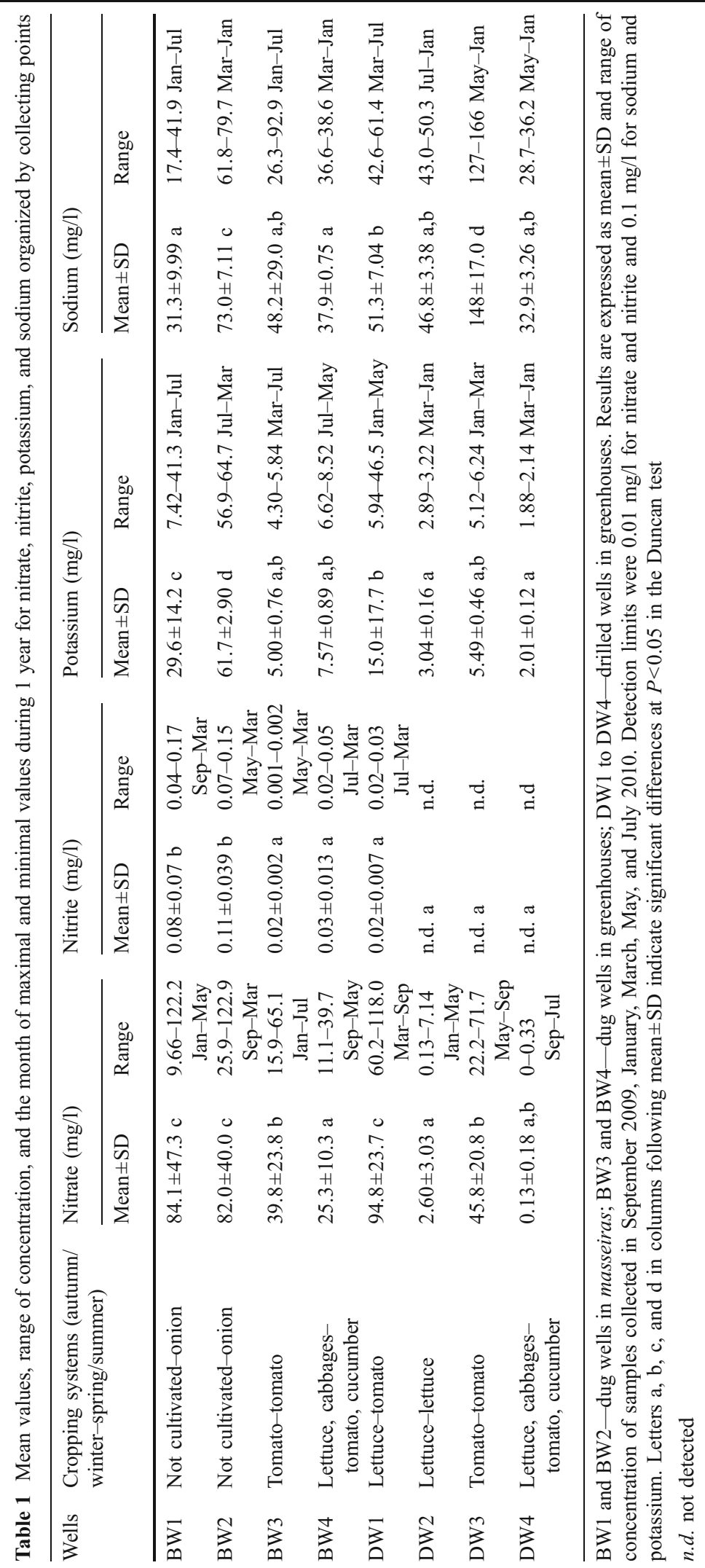


Table 2 Occurrence of pesticides in all water samples $(N=40)$

\begin{tabular}{|c|c|c|c|c|c|c|c|c|}
\hline \multirow[t]{2}{*}{ Abbreviation } & \multirow[t]{2}{*}{ Pesticides } & \multirow[t]{2}{*}{ Use } & \multirow[t]{2}{*}{ LOD } & \multirow[t]{2}{*}{ LOQ } & \multicolumn{4}{|c|}{ Number of samples $(N)$} \\
\hline & & & & & $N<$ LOD & $\mathrm{LOD}<N<\mathrm{LOQ}$ & $N>$ LOQ & $N>100 \mathrm{ng} / 1$ \\
\hline Ac & Acetamiprid & Insecticide & 15.6 & 52.0 & 40 & 0 & 0 & 0 \\
\hline Ad & Atrazinedesethyl & Herbicide & 8.3 & 27.6 & 28 & 6 & 6 & 4 \\
\hline $\mathrm{Al}$ & Aldrin & Insecticide & 8.3 & 27.8 & 39 & 0 & 1 & 1 \\
\hline Atz & Atrazine & Herbicide & 5.9 & 19.8 & 32 & 3 & 5 & 1 \\
\hline $\mathrm{Az}$ & Azoxystrobin & Fungicide & 5.7 & 19.2 & 19 & 10 & 11 & 1 \\
\hline $\mathrm{Cp}$ & Cyprodinil & Fungicide & 0.6 & 2.1 & 22 & 3 & 16 & 1 \\
\hline $\mathrm{Cr}$ & Cyromazine & Insecticide & 7.0 & 23.2 & 37 & 1 & 2 & 1 \\
\hline Dd & Dieldrin & Insecticide & 5.9 & 19.5 & 37 & 1 & 2 & 1 \\
\hline DDT & $o, p^{\prime}$-DDT & Insecticide & 4.7 & 15.6 & 38 & 1 & 1 & 0 \\
\hline $\mathrm{Dm}$ & Dimethoate & Insecticide & 4.8 & 16.1 & 34 & 0 & 6 & 2 \\
\hline $\mathrm{E}$ & Endrin & Insecticide & 8.4 & 28.2 & 40 & 0 & 0 & 0 \\
\hline ЕРТC & EPTC & Herbicide & 8.6 & 28.6 & 38 & 0 & 2 & 0 \\
\hline Fn & Fenhexamid & Fungicide & 19.0 & 63.5 & 37 & 0 & 3 & 3 \\
\hline Fo & Folpet & Fungicide & 16.7 & 55.8 & 27 & 5 & 8 & 5 \\
\hline $\mathrm{Fu}$ & Fludioxonil & Fungicide & 4.7 & 15.6 & 30 & 4 & 6 & 3 \\
\hline I & Iprodione & Fungicide & 6.7 & 22.2 & 37 & 1 & 2 & 0 \\
\hline $\mathrm{L}$ & Linuron & Herbicide & 7.9 & 26.4 & 39 & 1 & 0 & 0 \\
\hline $\mathrm{Mc}$ & Methoxychlor & Insecticide & 7.5 & 24.9 & 39 & 0 & 1 & 0 \\
\hline $\mathrm{Mt}$ & $S$-Metolachlor & Herbicide & 19.9 & 66.3 & 39 & 1 & 0 & 0 \\
\hline $\mathrm{Mx}$ & Metalaxyl & Fungicide & 9.9 & 33.1 & 25 & 1 & 14 & 9 \\
\hline $\mathrm{Pe}$ & Pendimethalin & Herbicide & 7.6 & 25.4 & 40 & 0 & 0 & 0 \\
\hline $\mathrm{Ph}$ & Phosmet & Insecticide & 13.90 & 46.20 & 40 & 0 & 0 & 0 \\
\hline $\mathrm{Pi}$ & Pirimicarb & Insecticide & 1.3 & 4.4 & 19 & 6 & 15 & 0 \\
\hline $\mathrm{T}$ & Terbuthylazine & Herbicide & 3.7 & 12.3 & 32 & 3 & 5 & 5 \\
\hline $\mathrm{Td}$ & Terbuthylazinedesethyl & Herbicide & 3.5 & 11.5 & 32 & 4 & 4 & 4 \\
\hline $\mathrm{Th}$ & Thiamethoxam & Insecticide & 6.4 & 21.2 & 26 & 0 & 14 & 8 \\
\hline To & Tolyfluanid & Fungicide & 12.4 & 41.2 & 39 & 0 & 1 & 1 \\
\hline $2,4-\mathrm{D}$ & $2,4-\mathrm{D}$ & Herbicide & 5.8 & 19.5 & 40 & 0 & 0 & 0 \\
\hline
\end{tabular}

LOD and LOQ values are given in nanograms per liter

$L O D$ limit of detection, $L O Q$ limit of quantification

presents the dendrogram obtained when clustering samples of dug wells and drilled wells according to frequency of pesticides quantified in each collection date. From observation of Fig. 2, a group composed by DW2, DW3, and DW4 is clearly identified. This association seems logical since it includes three collecting points that presented lower amounts of pesticides. The distribution pattern clearly shows that collection points DW2 and DW3 were characterized by a relatively homogeneous composition, both in time and space. A second cluster includes the samples from dug wells. Indeed, this group comprises samples that present higher amounts of insecticides and fungicides. The third cluster is formed by samples from one drilled wells that is clearly different from others and presents high amounts of herbicides.

For a more comprehensive insight into the studied area, PCA was performed using the concentrations of the 17 pesticides considered. PCA helps to find out why one sample is different from another, which variables contribute most to this difference, and whether those variables contribute in the same way 


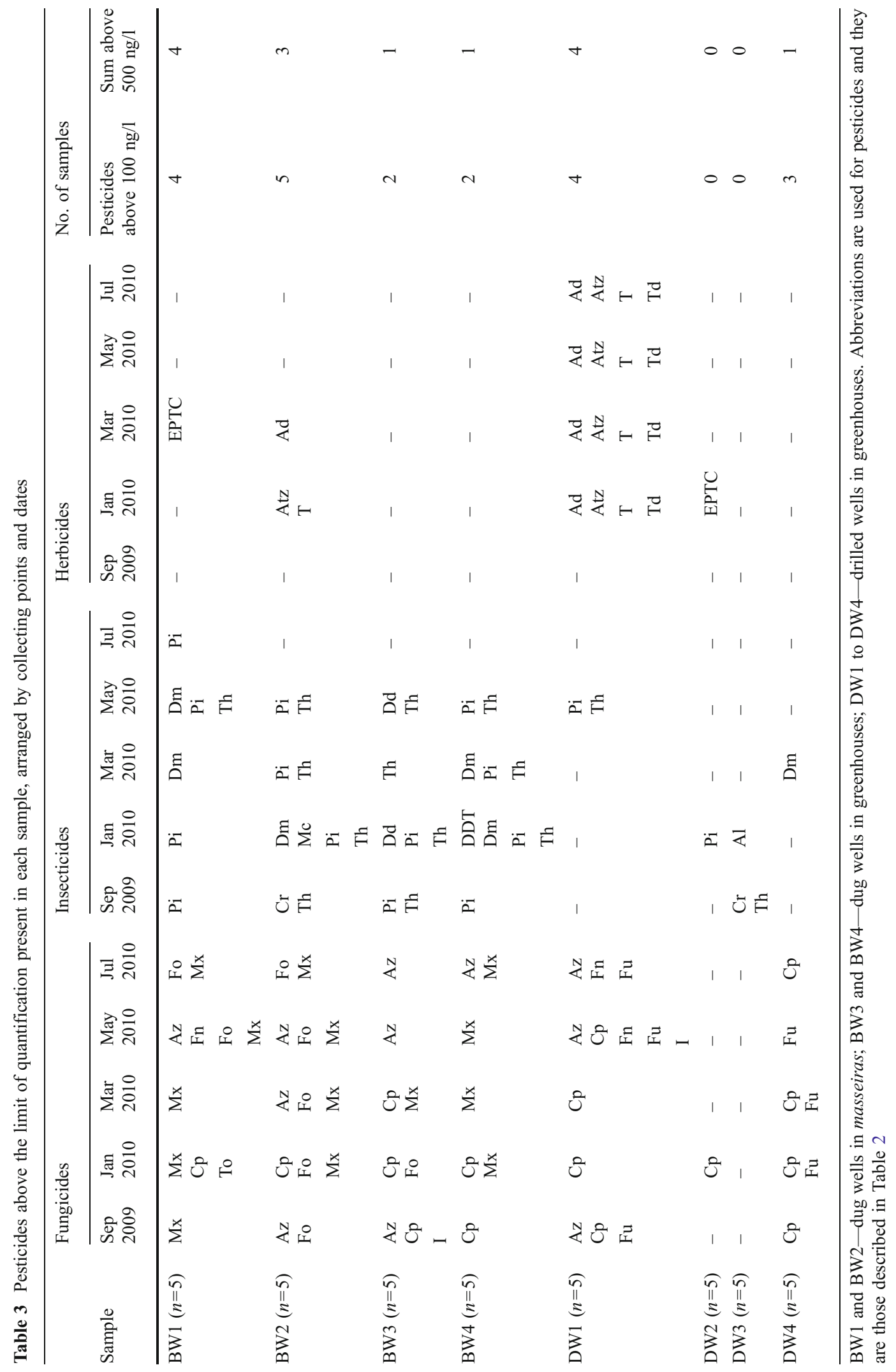


Fig. 2 Dendrogram produced by cluster analysis of data organized with eight rows corresponding to the four dug wells and four drilled wells and the column vectors $(\mathrm{X} 1, \mathrm{X} 2, \mathrm{X} 3, \mathrm{X} 4$,

$\mathrm{X} 5)$ representing the frequency of pesticides above the LOQ in each collection date. Single linkage method with Euclidean distances was used

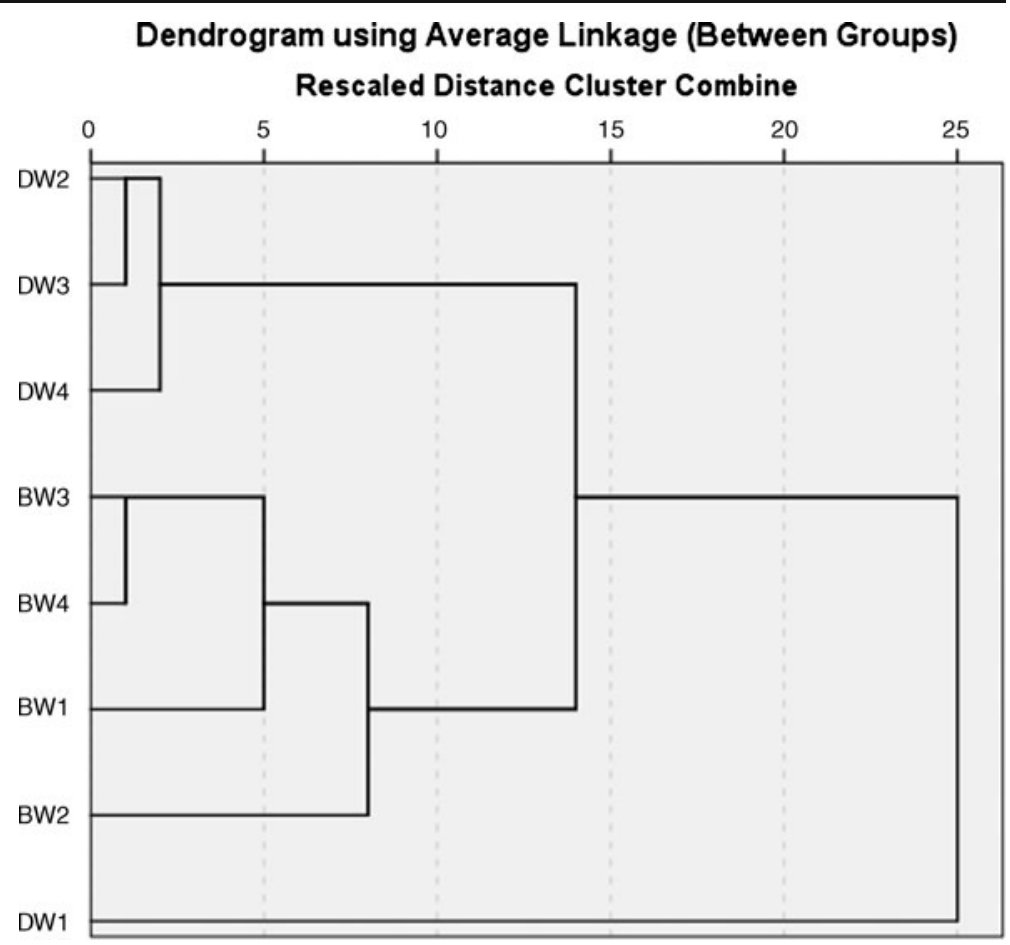

(i.e., are positively correlated) or are inversely correlated. Only factors exhibiting an eigenvalue above 1 were retained. Seven PCs were extracted which account for a total variance of $77.67 \%$. The Bartlett's sphericity test carried out on the correlation matrix of variables show a significant chi-square 793, indicating that PCA can achieve a significant reduction of the dimensionality of the original data set.
Table 4 shows the results of PCA with the eigenvalues, the corresponding amount of variance extracted, and most significant variable loadings. The score plot of the first two PCs is presented in Fig. 3. The PC1 (accounting for $20.89 \%$ variance of the total variance) receives a predominant loading from terbuthylazine, atrazinedesethyl, terbuthylazinedesethyl, atrazine, and fenhexamid. PC1 is almost entirely
Table 4 PCA results for groundwater set

\begin{tabular}{lclcc}
\hline Component & Eigenvalue & Variables & Loadings & Variance (\%) \\
\hline PC1 & 3.551 & Terbuthylazine & 0.898 & 20.888 \\
& & Terbuthylazinedesethyl & 0.894 & \\
& & Atrazinedesethyl & 0.847 & \\
& & Atrazine & 0.645 & \\
PC2 & & Fenhexamid & 0.643 & \\
& 2.594 & Thiamethoxam & 0.819 & 15.256 \\
PC3 & Folpet & 0.752 & \\
& & Pirimicarb & 0.655 & \\
PC4 & & Cyprodinil & 0.901 & 11.315 \\
PC5 & 1.924 & Fludioxonil & 0.901 & \\
PC6 & 1.474 & Azoxystrobin & 0.554 & 8.672 \\
PC7 & 1.373 & Dieldrin & -0.551 & 8.079 \\
& 1.262 & Dimethoate & 0.618 & 7.421 \\
& 1.027 & Cyromazine & 0.658 & 6.043 \\
& & Metalaxyl & -0.556 & \\
\hline
\end{tabular}


Fig. 3 Score plot of the first two PCs performed using the concentrations of pesticides. BW1, BW2, BW3, BW4 - dug wells; DW1, DW2, DW3, DW4-drilled wells

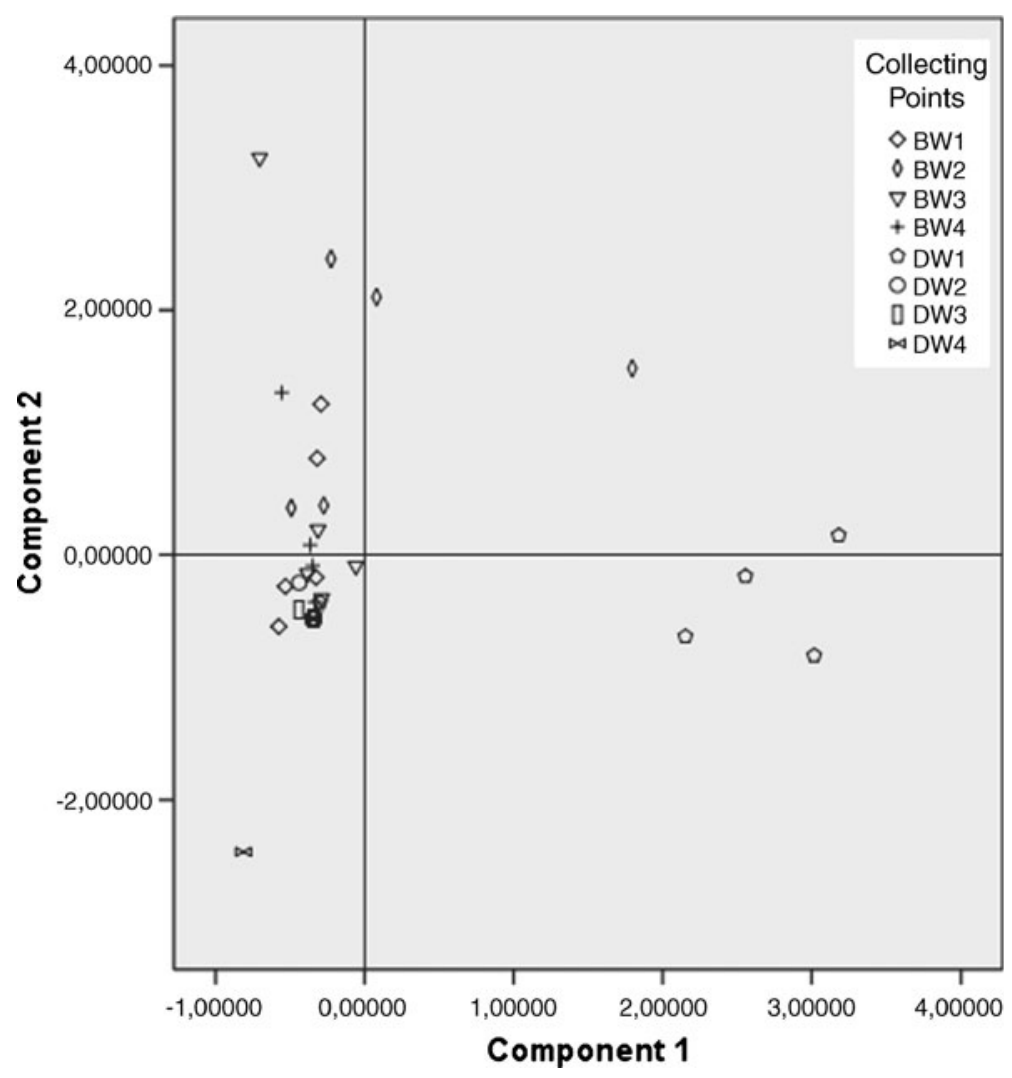

related with samples that present quantifiable amounts of two persistent herbicides and respective degradation. These samples were from samples DW1 close to a greenhouse dedicated to lettuce and other vegetables production that does not use herbicides. The source might be neighboring maize fields. This was also observed by other authors (Gonçalves et al. 2007). The second principal component, PC2, was mostly loaded with thiamethoxam, folpet, and pirimicarb and explained $15.26 \%$ of the variance. These compounds are widely used in intensive horticulture practices. For example, pirimicarb is a broadly used insecticide mainly sprayed against aphids; aphids are typically a spring pest but, due to climate changes, the mild temperatures observed in autumn and winter permit colonies of aphids almost all year. It is authorized in lettuce, beans, pepper, and potato. Samples from drilled wells, except those from DW1, were located in the third quadrant of the graphic during all sampling collection dates indicating low content of terbuthylazine, atrazinedesethyl, terbuthylazinedesethyl, atrazine, fenhexamid, thiamethoxam, folpet, and pirimicarb, whereas samples from dug wells were located on third and second quadrants (BW1, BW3, and BW4) and on second and third quadrants (BW2). Dug well contamination is strongly influenced by

Table 5 Classification functions and matrix for stepwise discriminant analysis of collecting points variation

\begin{tabular}{|c|c|c|c|c|}
\hline \multicolumn{5}{|c|}{ Standardized canonical discriminant function coefficients } \\
\hline \multicolumn{3}{|l|}{ Parameters } & \multicolumn{2}{|c|}{ Function } \\
\hline & & & 1 & 2 \\
\hline \multicolumn{3}{|l|}{ Nitrates } & 1.122 & -0.747 \\
\hline \multicolumn{3}{|l|}{ Sodium } & -0.655 & 0.791 \\
\hline \multicolumn{3}{|c|}{ Terbuthylazinedesethyl } & 0.889 & 0.401 \\
\hline \multicolumn{3}{|l|}{ Pirimicarb } & -0.605 & -0.178 \\
\hline \multicolumn{5}{|c|}{ Classification matrix } \\
\hline \multirow[t]{2}{*}{ CA groups ${ }^{\mathrm{a}}$} & $\%$ correct & \multicolumn{3}{|c|}{ Predicted group membership } \\
\hline & & 1 & 2 & 3 \\
\hline 1 & 100 & 15 & 0 & 0 \\
\hline 2 & 85 & 3 & 17 & 0 \\
\hline 3 & 80 & 0 & 1 & 4 \\
\hline Total & 90 & 18 & 18 & 4 \\
\hline
\end{tabular}

${ }^{\mathrm{a}}$ Group 1-DW2, DW3, DW4; group 2-BW1, BW2, BW3, BW4; and group 3-DW1 
local agricultural practices. Consequently, dug wells located in the same fields than drilled wells showed higher variation on pesticides content throughout the studied period. The third PC (PC3, 11.32\%) received loadings mainly from cyprodinil and fludioxonil; this is not particularly surprising, since the active ingredients are found together in fungicide formulations. The fourth PC (PC4, 8.67\%) can be mainly explained by azoxystrobin, a fairly employed fungicide, namely for tomato and lettuce. PC5 (8.07\%) and PC6 (7.42\%) are discerned mainly due to the behavior of two different insecticides, dieldrin (forbidden), and dimethoate (not used in vegetable production), respectively. PC7 $(6.04 \%)$ is related with cyromazine and metalaxyl. Metalaxyl is a widely used systemic fungicide used for downy mildews. The remaining $22.33 \%$ of data variance could not be clearly interpreted, due to great variability of farming practices, narrow neighboring closeness, and high vegetable replacement.

Global statistical analysis of data set

DA was performed with data set comprised of 17 pesticides, nitrate, potassium, and sodium after grouping into three major groups of wells distribution as obtained through CA. The clusters were the three grouping (dependent) variables, while the measured parameters constituted the independent variables. The discriminant functions and classification matrices were obtained by stepwise method. DA rendered the corresponding classification matrices assigning 90\% cases correctly using only four discriminant parameters (Table 5). These results suggested that nitrates, sodium, terbuthylazinedesethyl, and pirimicarb are the most significant parameters to discriminate between the three different groups of wells (group 1-DW2, DW3, DW4; group 2-BW1, BW2, BW3, BW4; and group 3DW1). The correct assignations (90\%) by DA for the three different site clusters (groups 1,2, and 3) further confirmed the adequacy of DA and that grouping pattern coincides with previous results from CA. Both $\mathrm{CA}$ and DA predict important differences in water composition from drilled wells, except DW1 and dug wells. Thus, CA helped to group the eight collecting points into three clusters of similar characteristics pertaining to water contamination. Extracted grouping information can be of use in reducing the number of sampling sites without missing much information.

\section{Conclusions}

In conclusion, cluster and discriminant analysis grouped the eight collecting points into three clusters of similar characteristics pertaining to water contamination. Nitrate and pesticide residues found in groundwater show that improvement of cultural practices are required in zones of intense horticulture production. Inorganic fertilizers such as potassium nitrate were suspected to be the most important factors for nitrate contamination. The most frequent fungicides were cyprodinil, metalaxyl, and azoxystrobin, whereas the most frequent insecticides were pirimicarb and thiamethoxam, followed by dimethoate, dieldrin, cyromazine, $o, p^{\prime}$-DDT, methoxychlor, and aldrin. The most frequent herbicides were atrazine and terbuthylazine and their desethyl metabolites. It should be pointed out that some pesticides not in use nowadays were detected in some samples. Water from dug wells is especially prone to contamination from the grower and their closer neighbor's practices. Water from drilled wells is contaminated from close cultural practices and also from distant practices probably due to the occurrence of an unconfined aquifer below the entire region.

Acknowledgments Our thanks to Inês Ramos and growers of Horpozim in Aguçadoura for facilitating the collection of water samples. Two of the authors (A. Melo and E. Pinto) want to thank FCT (Portuguese Foundation for Science and Technology) for Ph.D. grant SFRH/BD/41764/2007 and SFRH/BD/67042/ 2009, respectively. This work has been supported by Project PTDC/AGR-ALI/101583/2008.

\section{References}

Agostinho, J. M. (2006). Avaliação de técnicas para redução das perdas de azoto nos sistemas agrícolas da zona vulnerável do aquífero livre de Esposende e Vila do Conde. Ph.D. Dissertation, ISA-UTL, Lisbon.

Altieri, M., \& Nicholls, C. (2005). Agroecology and the search for a truly sustainable agriculture. Mexico: University of California, Berkeley.

Andrade, E. M., Palácio, H. A. Q., Crisóstomo, L. A., Souza, I. H., \& Teixeira, A. S. (2005). Índice de qualidade de água, uma proposta para o vale do rio Trussu, Ceará. Revista Ciência Agronômica, 36(2), 135-142.

Bouwer, H. (2000). Integrated water management: Emerging issues and challenges. Agricultural Water Management, $45,217-228$.

Chowdary, V. M., Rao, N. H., \& Sarma, P. B. S. (2005). Decision support framework for assessment of non-point- 
source pollution of groundwater in large irrigation projects. Agricultural Water Management, 75, 194-225.

Council Directive 91/676/EEC. (1991). Concerning the protection of waters against pollution caused by nitrates of agricultural sources. Official Journal of the European Union.

DGADR. (2009). Pesticidas a pesquisar em 2010 em águas para consumo humano. Lisbon: Direcçao-Geral de Agricltura e Desenvolvimento Rural.

Directive 2006/118/EC. (2006). Protection of groundwater against pollution and deterioration. Official Journal of the European Union.

Gangopadhyay, S., Gupta, A., \& Nachabe, M. H. (2001). Evaluation of groundwater monitoring network by principal component analysis. Ground Water, 39(2), 181-191.

Gonçalves, C., Esteves da Silva, J. C. G., \& Alpendurada, M. F. (2006). Chemometric interpretation of pesticide occurrence in soil samples from an intensive horticulture area in north Portugal. Analytical Chimica, Acta, 560, 164-171.

Gonçalves, C. M., Esteves da Silva, J. C. G., \& Alpendurada, M. F. (2007). Evaluation of the pesticide contamination of groundwater sampled over two years from a vulnerable zone in Portugal. Journal of Agricultural and Food Chemistry, 55, 6227-6235.

Kundu, M. C., Mandal, B., \& Hazra, G. C. (2009). Nitrate and fluoride contamination in groundwater of an intensively managed agroecosystem: A functional relationship. Science of the Total Environment, 407, 2771-2782.

Mansilha, C., Melo, A., Rebelo, H., Heitor, A., Ferreira, I. M. P. L. V. O., Pinho, O., et al. (2010). Quantification of endocrine disruptors and pesticides in water by gas chromatography-tandem mass spectrometry. Method validation using weighted linear regression schemes. Journal of Chromatography A, 1217(43), 6681-6691.

Pinto, E., Petisca, C., Amaro, L. F., Pinho, O., \& Ferreira, I. M. P. L. V. O. (2010). Influence of different extraction conditions and sample pretreatments on quantification of nitrate and nitrite in spinach and lettuce. Journal of Liquid Chromatography and Related Technologies, 33, 1-12.
Portaria $n^{\circ} 556 / 2003$. Approves the action program for the vulnerable zone $\mathrm{n}^{\mathrm{o}} .1$, constituted by the free aquifer between Esposende and Vila do Conde. DR 159 Série I-B 2003.

Russak, A., \& Sivan, O. (2010). Hydrogeochemical tool to identify salinization or freshening of coastal aquifers determined from combined field work, experiments, and modeling. Environmental Science and Technology, 44, 4096-4102.

Silva, E., Batista, S., Viana, P., Antunes, P., Serdio, L., Cardoso, A. T., et al. (2006). Pesticides and nitrates in groundwater from oriziculture areas of the "Baixo Sado" region (Portugal). International Journal of Environmental Analytical Chemistry, 86, 955-972.

Simeonov, V., Stratis, J. A., Samara, C., Zachariadis, G., Voutsa, D., Anthemidis, A., et al. (2003). Assessment of the surface water quality in Northern Greece. Water Research, 37, 4119-4124.

Singh, K. P., Malik, A., \& Sinha, S. (2005). Water quality assessment and apportionment of pollution sources of Gomti river (India) using multivariate statistical techniques -a case study. Analytical Chimica Acta, 538(2), 355-374.

Squillace, P. J., Scott, J. C., Moran, M. J., Nolan, B. T., \& Kolpin, D. W. (2002). VOCs, pesticides, nitrate, and their mixtures in groundwater used for drinking water in the United States. Environmental Science and Technology, 36, 1923-1930.

Szymanska-Pulikowska, A. (2008). Sodium and potassium in the groundwater in areas near the Maslice municipal refuse dump in Wroclaw. Journal Elementology, 13, 665-673.

UNEP. (2005). United Nations Environment Programme. Ridding the world of POPs: A guide to the Stockholm Convention on Persistent Organic Pollutants. Switzerland: Secretariat of the Stockholm Convention.

Wunderlin, D. A., Diáz, M. P., Amé, M. V., Pesce, S. F., Hued, A. C., \& Bistoni, M. L. A. (2001). Pattern recognition techniques for the evaluation of spatial and temporal variations in water quality. A case study: Suquá river basin (Córdoba-Argentina). Water Research, 35(1), 2881-2894. 